This item was submitted to Loughborough's Research Repository by the author.

Items in Figshare are protected by copyright, with all rights reserved, unless otherwise indicated.

\title{
High thermoregulatory strain during competitive paratriathlon racing in the
} heat

PLEASE CITE THE PUBLISHED VERSION

https://doi.org/10.1123/ijspp.2019-0116

\section{PUBLISHER}

(C) Human Kinetics

VERSION

AM (Accepted Manuscript)

\section{PUBLISHER STATEMENT}

This work is made available according to the conditions of the Creative Commons Attribution-NonCommercialNoDerivatives 4.0 International (CC BY-NC-ND 4.0) licence. Full details of this licence are available at: https://creativecommons.org/licenses/by-nc-nd/4.0/

\section{LICENCE}

CC BY-NC-ND 4.0

\section{REPOSITORY RECORD}

Stephenson, Ben T., Sven P. Hoekstra, Keith Tolfrey, and Vicky Goosey-Tolfrey. 2019. "High Thermoregulatory Strain During Competitive Paratriathlon Racing in the Heat". figshare. https://hdl.handle.net/2134/37730. 


\section{High thermoregulatory strain during competitive paratriathlon 2 racing in the heat}

\section{Original Investigation}

4 Ben T. Stephenson ${ }^{1,2}$, Sven P. Hoekstra ${ }^{1}$, Keith Tolfrey ${ }^{1}$ and Victoria L. Goosey-Tolfrey ${ }^{1}$ 5

$6{ }^{1}$ The Peter Harrison Centre for Disability Sport, School of Sport, Exercise \& Health Sciences, 7 Loughborough University, Loughborough, LE11 3TU, UK

$8{ }^{2}$ English Institute of Sport, Loughborough Performance Centre, Loughborough University,

9 Loughborough, LE11 3TU, UK

10

11 Corresponding author:

12 Prof. Victoria Goosey-Tolfrey

13 The Peter Harrison Centre for Disability Sport,

14 School of Sport, Exercise \& Health Sciences,

15 Loughborough University,

16 Loughborough,

17 LE11 3TU,

18 UK

19 Email: v.l.tolfrey@lboro.ac.uk

20 Phone +44 (0) 1509226386

21

22 Running head: Paratriathlon competition in the heat

23 Abstract word count: 217

24 Word count: 2945 


\section{High thermoregulatory strain during competitive paratriathlon 27 racing in the heat}

\section{ABSTRACT}

Purpose: Paratriathletes may display impairments in autonomic (sudomotor and/or vasomotor function) or behavioural (drinking and/or pacing of effort) thermoregulation. As such, this study aimed to describe the thermoregulatory profile of athletes competing in the heat.

Methods: Core temperature $\left(T_{c}\right)$ was recorded at $30 \mathrm{~s}$ intervals in 28 mixed-impairment paratriathletes during competition in a hot environment $\left(33^{\circ} \mathrm{C}, 35-41 \%\right.$ relative humidity, 25 $27^{\circ} \mathrm{C}$ water temperature), via an ingestible temperature sensor (BodyCap e-Celsius). Furthermore, in a subset of 9 athletes, skin temperature $\left(\mathrm{T}_{\mathrm{sk}}\right)$ was measured. Athletes' wetsuit use was noted whilst heat illness symptoms were self-reported post-race.

Results: Twenty-two athletes displayed a $\mathrm{T}_{\mathrm{c}} \geq 39.5^{\circ} \mathrm{C}$ with 8 athletes $\geq 40.0^{\circ} \mathrm{C}$. There were increases across the average $T_{c}$ for swim, bike and run sections $(p \leq 0.016)$. There was no change in $T_{\text {sk }}$ during the race $(p \geq 0.086)$. Visually impaired athletes displayed a significantly greater $T_{\mathcal{c}}$ during the run section than athletes in a wheelchair $(p \leq 0.021)$. Athletes wearing a wetsuit $(57 \%$ athletes) had a greater $T_{\mathcal{c}}$ when swimming $(p \leq 0.032)$ whilst those reporting heat illness symptoms (57\% athletes) displayed a greater $\mathrm{T}_{\mathrm{c}}$ at various timepoints $(p \leq 0.046)$.

Conclusions: Paratriathletes face significant thermal strain during competition in the heat, as evidenced by high $T_{c}$, relative to previous research in able-bodied athletes, and a high incidence of self-reported heat illness symptomatology. Differences in the $T_{\mathfrak{c}}$ profile exist depending on athletes' race category and wetsuit use.

48 Key words: Thermoregulation, disability, triathlon, elite, Paralympic 


\section{INTRODUCTION}

Paralympic athletes are a population group with unique challenges in autonomic or behavioural thermoregulatory function, relative to able-bodied (AB) athletes. Whilst this has been acknowledged by researchers, ${ }^{1}$ there is still a dearth of research in elite athletes with physical impairments. The finite literature concerning thermoregulation in Paralympic sport has centred on athletes with a spinal cord injury (SCI) due to their high propensity for thermal strain caused by impaired autonomic function and therefore sudomotor and vasomotor control. ${ }^{2}$ Research has characterised the thermoregulatory responses to wheelchair rugby and tennis, ${ }^{2,3}$ whilst a case study exists in a single handcyclist. ${ }^{4}$ However, other impairment groups are also at risk of thermal strain. Athletes with amputations, neurological impairments or visual impairments face: limited body surface area for heat loss due to missing limbs, skin grafts or wearing prosthetic liners; ${ }^{1,5,6}$ increased metabolic heat production from movement inefficiencies; ${ }^{7,8}$ weakened venous return from high muscular tone or paralysed muscle, ${ }^{9,10}$ and impaired pace or hydration awareness. ${ }^{10,11}$ Yet, these impairments are severely understudied despite athletes' commonality in Paralympic sports and similarly increased risk of thermal strain.

Competitive events in paratriathlon, the Paralympic variant of triathlon, are commonly held in environments with high ambient temperatures; however, prolonged exercise in hot environments limits the capacity of the body to dissipate heat. ${ }^{12}$ As heat gain exceeds heat loss elevations in core $\left(\mathrm{T}_{\mathrm{c}}\right)$ and skin $\left(\mathrm{T}_{\mathrm{sk}}\right)$ temperature occur. Such elevations have been attributed to well-documented performance impairments in the heat through central and peripheral processes. ${ }^{13}$ Furthermore, elevated body temperatures have been implicated in the development of heat illness. ${ }^{14}$ Whilst laboratory-based studies have defined the thermoregulatory strain imposed on athletes exercising in the heat, ${ }^{15}$ these studies lack applicability to field-based competitive races. ${ }^{14,16,17}$ Consequently, research has sought to typify outdoor competition. ${ }^{14}$, 17-20 This is in accordance with the recommendations to characterise the sport- and eventspecific thermal strain profiles of international athletes competing in the heat to improve athletes' safety. ${ }^{21}$

Several studies have now presented the thermoregulatory responses to able-bodied (AB) triathlon races of varying distances. ${ }^{14,18,19,22}$ This work has shown that AB triathletes' $\mathrm{T}_{\mathrm{c}}$ can reach $38.4 \pm 0.7^{\circ} \mathrm{C}^{18}$ to $38.8 \pm 0.7^{\circ} \mathrm{C}^{19}$ at the end of half-Ironman races in the heat (27$29^{\circ} \mathrm{C}$ ). Additionally, by acquiring in-race $\mathrm{T}_{\mathrm{c}}$ readings, Baillot and $\mathrm{Hue}^{18}$ presented a trend for $\mathrm{T}_{\mathrm{c}}$ changes across swim, bike and run sections. In shorter distance racing, with a presumed greater relative exercise intensity and less opportunities for fluid consumption more akin to paratriathlon, Logan-Sprenger present data in a small group of Olympic $(n=4)$ and sprint distance triathletes $(n=1) .{ }^{22}$ Even in cool conditions $\left(\sim 19^{\circ} \mathrm{C}\right), \mathrm{T}_{\mathrm{c}}$ reached $39.2 \pm 0.4^{\circ} \mathrm{C}$ and this was accompanied by two of the athletes with $\mathrm{T}_{\mathrm{c}} \geq 39.2^{\circ} \mathrm{C}$ reporting symptoms of heat illness post-race. ${ }^{22}$ Nonetheless, data are still restricted to infrequent $T_{c}$ sampling, commonly pre- and post-race measurement, during field-based research. Furthermore, although studies have attempted to determine the correlates to in-race $T_{c}$ such as fluid intake or race performance, ${ }^{14}$, $16-18,23$ as no study has researched Paralympic athletes, it is not possible to discern any relationship between physical impairment and thermal strain imposed. Thus, it is pertinent to better describe the thermoregulatory strain profiles of paratriathletes using ingestible temperature pills, in line with the recommendations of Bergeron et $a l^{21}$, and determine the risk to athletes' health through heat illness genesis. Consequently, the aims of this study were to characterise the $\mathrm{T}_{\mathrm{c}}$ and $\mathrm{T}_{\mathrm{sk}}$ responses to paratriathlon competition in the heat. 


\section{Participants}

97 Twenty-eight paratriathletes volunteered to participate in the present study (Table 1). Athletes' 98 paratriathlon world ranking at the time of the study was $1^{\text {st }}$ to $24^{\text {th }}$ place. Athletes were 99 competing in the 2017 Iseo-Franciacorta ITU Paratriathlon World Cup ( $8^{\text {th }}$ July) or 2018 Iseo-

100 Franciacorta ITU World Paratriathlon Series ( $30^{\text {th }}$ June) (Iseo, Lombardy, Italy; elevation 185 $101 \mathrm{~m})$. Athletes were asked to provide details of their training for the preceding four weeks to determine heat acclimatisation or acclimation status. Those who reported daily, or alternate days, training in temperatures $\geq 30.0^{\circ} \mathrm{C}$ for $\geq 60 \mathrm{~min} \cdot \mathrm{d}^{-1}$, with a total number of heat exposures $\geq 5$ were classed as heat acclimated/acclimatised, dependent on the training environment. Athletes provided written informed consent and the procedures were approved by the Loughborough University Ethical Advisory Committee in the spirit of the Helsinki Declaration.

\section{Methodology}

110 The race consisted of a single lap, $750 \mathrm{~m}$ open-water lake swim, $21 \mathrm{~km}$ (3 laps of $7 \mathrm{~km})$ nondrafting cycle and a $4.8 \mathrm{~km}$ run (2017: 3 laps of $1.6 \mathrm{~km}$; 2018: 4 laps of $1.2 \mathrm{~km}$ ). The cycle course was largely flat with an elevation change of $\sim 49 \mathrm{~m}$ per lap. The races started between 16:00-16:30 (2017 event) and 17:00-18:30 local time (2018 event), depending on athletes' race category. Environmental conditions during the 2017 race were: $33^{\circ} \mathrm{C}$ air temperature, $41 \%$ relative humidity, $27^{\circ} \mathrm{C}$ water temperature and $11 \mathrm{~km} \cdot \mathrm{h}^{-1}$ wind velocity and during the 2018 race were: $33^{\circ} \mathrm{C}$ air temperature, $35 \%$ relative humidity, $25^{\circ} \mathrm{C}$ water temperature and 18 $\mathrm{km} \cdot \mathrm{h}^{-1}$ wind velocity (RH390, Extech Instruments, Nashua, NH, USA). The cloud cover, whilst not measured, was minimal, and no precipitation was recorded during either race. Due to the similar environmental conditions, data were pooled into one group. All athletes wore a swimcap when swimming. Twelve athletes wore a trisuit for the whole race, with cycling shoes during cycling and trainers when running, whilst sixteen athletes chose to additionally wear a wetsuit during the swim stage. Aligned to ITU paratriathlon competition rules, PTWC athletes used a handbike and racing wheelchair for bike and run sections, respectively, whilst PTVI athletes raced with an $\mathrm{AB}$ guide and used a tandem bicycle. Ambulant sport categories (PTS2PTS5) used prostheses or adaptations to bicycles, where necessary.

Athletes were provided with a telemetric $\mathrm{T}_{\mathrm{c}}$ pill (e-Celsius, BodyCap, Caen, France) which they were asked to ingest $\sim 6 \mathrm{~h}$ pre-race. ${ }^{24}$ Whilst differences in gastrointestinal transit time were likely present among individuals, especially considering the potential effects of athletes' impairments, a standardised ingestion timing was employed to align with previous research, ${ }^{16-18,} 22$ including studies in athletes with an SCI. ${ }^{2}$ The e-Celsius device permitted remote temperature measurement and storage without the need for constant communication to a receiving monitor. Although no individual calibration of pills was performed, previous research has shown the equipment to be highly accurate and reliable. ${ }^{25} \mathrm{~T}_{\mathrm{c}}$ was recorded at $30 \mathrm{~s}$ intervals thus providing a greater sampling frequency than previous field-based studies. ${ }^{23}$ Athletes were free to warm-up and complete the race as normal. Similarly, athletes were free to consume fluids ad libitum during the race, but intake was self-reported post-race. Due to the logistical demands of studying elite athletes in-competition, and the challenges associated with weighing athletes with physical impairments, it was not possible to collect meaningful body mass changes directly pre- and post-race. Immediately post-race, athletes reported to investigators for wireless $T_{c}$ data download. Athletes were asked to state if they had felt any symptoms of heat illness during the race such as confusion, dizziness, fainting, muscle or 
142 abdominal cramps, nausea, vomiting, diarrhoea, heat sensations on the head or neck, chills or stopping sweating. ${ }^{26}$

In a subset of 9 athletes, $\mathrm{T}_{\mathrm{sk}}$ was measured via temperature loggers (DS1922L Thermochron iButton ${ }^{\circledR}$; Maxim Integrated Products, Inc., Sunnyvale, CA, USA) placed on the pectoralis major and rectus femoris muscle belly under waterproof adhesive patches (Tegaderm $+\mathrm{Pad}, 3 \mathrm{M}$, St. Paul, MN, USA). This permitted the calculation of weighted mean $\mathrm{T}_{\mathrm{sk}}$ using an adaptation of the methods of Ramanathan ${ }^{27}$ whereby $\mathrm{T}_{\mathrm{sk}}$ was taken as 0.6 (pectoralis major temperature) +0.4 (rectus femoris temperature). These sites were chosen to minimise any distraction to athletes when racing and the risk of loggers coming loose. No athletes in whom $\mathrm{T}_{\mathrm{sk}}$ was measured wore a wetsuit during the swim section. Due to the inability to fully insulate thermocouples and minimise convective heat transfer during swimming, $\mathrm{T}_{\mathrm{sk}}$ data from the swim section were not included in data analysis.

\section{Data analyses}

Athletes were grouped based on their impairment into one of four groups: PTWC for wheelchair athletes $(n=9)$, NEURO for athletes with a neurological impairment ( $n=6$ PTS2 and PTS3 athletes), AMP for athletes with an amputation ( $n=7$ PTS2-PTS5 athletes) and PTVI for athletes with a visual impairment $(n=6)$. They were also grouped based on self-reported heat acclimatisation/acclimation status, heat illness symptomatology and wetsuit use.

Athletes' segment times for swim, bike, run and transitions were recorded by the race organiser and published online. Athletes' $\mathrm{T}_{\mathrm{c}}$ during the race was averaged into modalityspecific segments for swim, bike, run and transitions: SWIM $\mathrm{av}_{\mathrm{av}} \mathrm{BIKE}_{\mathrm{av}}, \mathrm{RUN}_{\mathrm{av}}, \mathrm{T} 1, \mathrm{~T} 2$. Further, actual temperatures for immediately pre-race (PRE), the end of the swim (SWIM end $_{\text {), }}$ the end of each bike lap $\left(\mathrm{BIKE}_{1}, \mathrm{BIKE}_{2}, \mathrm{BIKE}_{3}\right)$, midway through the run section $\left(\mathrm{RUN}_{\mathrm{mid}}\right)$ and the end of the run ( $\left.\mathrm{RUN}_{\text {end }}\right)$ were calculated, assuming evenly paced efforts. Absolute changes in $T_{c}$ were calculated for each race segment: $\mathrm{SWIM}_{\Delta}, \mathrm{BIKE}_{\Delta}, \mathrm{RUN}_{\Delta}$.

\section{Statistical analyses}

All statistical analyses were conducted using SPSS Statistics 23.0 software (IBM, NY, USA). Statistical significance was set at $p<0.05$. Data were checked for normal distribution using the Shapiro-Wilk between-group test and for homogeneity of variance using Levene's test. Where sphericity could not be assumed, the Greenhouse-Geisser correction was used. Changes in $\mathrm{T}_{\mathrm{c}}$ and $\mathrm{T}_{\mathrm{sk}}$ during the race were assessed as a group via one-way repeated measures analysis of variance. Similarly, to determine any relationship with athletes' impairment group, acclimatisation/acclimation status, wetsuit use and reporting of heat illness symptoms, changes in $T_{c}$ were assessed via two-way repeated measures analysis of variance with group and time factors. The Bonferroni post-hoc test was used to evaluate pairwise comparisons of time points. Spearman's correlation coefficient was employed to determine the degree of correlation to peak $\mathrm{T}_{\mathrm{c}}$ from: $\mathrm{T}_{\mathrm{c}}$ during race time points; changes in $\mathrm{T}_{\mathrm{c}}$ across race segments; race performance; finishing position; fluid intake; body mass and paratriathlon world ranking. A paired-samples $\mathrm{t}$-test was used to determine differences in $\mathrm{T}_{\mathrm{sk}}$ changes between bike and run sections.

\section{RESULTS}

The mean \pm standard deviation time to complete the race was $74.9 \pm 11.2 \mathrm{~min}$ with a range of 54.6 to $103.9 \mathrm{~min}$. The times for swim, bike and run were $14.3 \pm 2.6 \mathrm{~min}$ (10.5 to $20.0 \mathrm{~min}$ ), $36.4 \pm 6.0 \mathrm{~min}$ (28.8 to $52.9 \mathrm{~min}$ ) and $21.1 \pm 5.1 \mathrm{~min}(13.1$ to $36.2 \mathrm{~min}$ ), respectively.

There was a significant change in $\mathrm{T}_{\mathrm{c}}$ over time when all athletes were pooled together. Specifically: PRE was lower than all other time points $(p<0.001)$; $\mathrm{RUN}_{\text {mid }}$ was greater than SWIM $_{\text {end }}$, T1 and T2 ( $\left.p \leq 0.039\right)$; RUN $N_{\text {end }}$ was greater than all other time points $(p \leq 0.031)$; whilst 
there was a significant increase across PRE, $\mathrm{SWIM}_{\mathrm{av}}, \mathrm{BIKE}_{\mathrm{av}}$ and $\mathrm{RUN}_{\mathrm{av}}(p \leq 0.016)$ (Figure 1). There was an impairment-specific interaction as $\mathrm{RUN}_{\Delta}$, changes in $\mathrm{T}_{\mathrm{c}} \mathrm{T} 2-\mathrm{RUN}_{\text {mid }}$ and RUN $\mathrm{mid}^{-}$ $\mathrm{RUN}_{\text {end }}$ were significantly greater for PTVI than PTWC $(p \leq 0.021)$ (Table 2).

Fourteen of the twenty-eight athletes reported being heat acclimatised/acclimated prior to the study. Those reporting being heat acclimatised/acclimated displayed a greater $\mathrm{RUN}_{\mathrm{end}}$ $\left(39.78 \pm 0.55\right.$ vs $\left.39.22 \pm 0.41^{\circ} \mathrm{C}\right)$ and change in $\mathrm{T}_{\mathrm{c}} \mathrm{RUN}_{\text {mid }}-\mathrm{RUN}_{\text {end }}(0.47 \pm 0.30$ vs $0.16 \pm$ $\left.0.14^{\circ} \mathrm{C}\right)(p \leq 0.044)$. Athletes that wore a wetsuit had significantly greater SWIMend $(38.76 \pm$ 0.40 vs $\left.38.31 \pm 0.40^{\circ} \mathrm{C}\right)$ and $\mathrm{SWIM}_{\mathrm{av}}\left(38.45 \pm 0.34\right.$ vs $\left.38.03 \pm 0.35^{\circ} \mathrm{C}\right)(p \leq 0.032)$. Sixteen athletes reported experiencing symptoms of heat illness during the race, of which ten wore a wetsuit. Those that were symptomatic had a significantly greater SWIM $_{\text {end }}$, SWIM $_{\mathrm{av}}, \mathrm{SWIM}_{\Delta}$ $\left(0.80 \pm 0.50\right.$ vs $\left.0.38 \pm 0.37^{\circ} \mathrm{C}\right), \mathrm{T} 1, \mathrm{BIKE}_{1}, \mathrm{BIKE}_{2}, \mathrm{BIKE}_{\mathrm{av}}$ and $\mathrm{RUN}_{\mathrm{av}}$ than those asymptomatic $(p \leq 0.046)$ (Figure 2).

Twenty-six out of twenty-eight athletes $(93 \%)$ reached a peak $\mathrm{Tc} \geq 39.0^{\circ} \mathrm{C}, 22$ athletes $\geq 39.5^{\circ} \mathrm{C}(79 \%), 8$ athletes $\geq 40.0^{\circ} \mathrm{C}(29 \%)$ and 2 athletes $\geq 40.5^{\circ} \mathrm{C}(7 \%)$. There were significant positive correlations between peak $\mathrm{T}_{\mathrm{c}}$ and: change in $\mathrm{T}_{\mathrm{c}} \mathrm{T} 1-\mathrm{BIKE}_{1}(p=0.001 ; r=0.629), \mathrm{BIKE}_{1}$ $(p<0.001 ; r=0.735), \mathrm{BIKE}_{2}(p<0.001 ; r=0.762), \mathrm{BIKE}_{3}(p=0.003 ; r=0.546), \mathrm{BIKE}_{\mathrm{av}}(p=0.001 ;$ $r=0.624), \mathrm{T} 2$ ( $p=0.016 ; r=0.475), \mathrm{RUN}_{\text {mid }}(p<0.001 ; r=0.845), \mathrm{RUN}_{\text {end }}(p<0.001 ; r=0.902)$, $\operatorname{RUN}_{\mathrm{av}}(p<0.001 ; r=0.871)$, change in $\mathrm{T}_{\mathrm{c}} \mathrm{RUN}_{\text {mid }}-\mathrm{RUN}_{\mathrm{end}}(p=0.036 ; r=0.420)$. There was no significant correlation between peak $\mathrm{T}_{\mathrm{c}}$ and overall race finishing time, race segment times, finishing position, fluid intake or body mass $(p \geq 0.143 ; r \leq 0.284)$.

There was no significant difference in $\mathrm{T}_{\text {sk }}$ over time ( $p=0.086$; Figure 3$)$. , However, there was a significant difference in the change in $\mathrm{T}_{\mathrm{sk}}$ across the bike and run sections, as the absolute change was greater during the bike than run $\left(-1.70 \pm 1.15\right.$ vs. $\left.1.03 \pm 1.67^{\circ} \mathrm{C} ; p=0.017\right)$.

\section{DISCUSSION}

This is the first study to characterise the thermoregulatory strain imposed by field-based paratriathlon performance in the heat via continuous $T_{c}$ measurement. Paratriathletes face significant thermoregulatory strain as shown by 22 of the 28 athletes displaying a peak $\mathrm{T}_{\mathrm{c}}$ $\geq 39.5^{\circ} \mathrm{C}$, of which were 8 athletes $\geq 40.0^{\circ} \mathrm{C}$. Furthermore, a high proportion of athletes $(57 \%)$ experienced self-reported symptoms of heat illness. This may be related to wetsuit use which effected the early rise in $\mathrm{T}_{\mathrm{c}}$ during the first phase of the race.

During competition, $\mathrm{T}_{\mathrm{c}}$ was significantly elevated from pre-race with marked increases during the run segment, as consistent with previous research of $\mathrm{AB}$ athletes. ${ }^{18}$ Moreover, considering race segment averages, there was a significant rise in $\mathrm{T}_{\mathrm{c}}$ throughout the race. Given the impairment types within paratriathlon, it was not surprising to find $\mathrm{T}_{\mathrm{c}}$ greater than previously reported in $\mathrm{AB}$ Olympic and sprint distance races in cool environments and halfIronman events in the heat. ${ }^{18,19,22}$ Paratriathletes may display myriad impairments that diminish thermoregulatory capacity and thus elevate $T_{c}$ during competition, relative to $A B$ athletes. Depending upon their impairment, paratriathletes may display a diminished capacity for evaporative heat loss, augmented metabolic heat production or impaired pace awareness, ${ }^{1}$, 5, 6, 7-11 thus elevating their risk of thermal strain and heat illness symptomatology., Due to the greater race durations for Olympic $(\sim 110)$ half-Ironman events $(\sim 320 \mathrm{~min})$ than is typical in paratriathlon races, the relative intensity is markedly lower in longer races, thus representing a discrepant metabolic heat production. ${ }^{28}$

The proportion of athletes with a peak $\mathrm{T}_{\mathrm{c}} \geq 39.0^{\circ} \mathrm{C}(93 \%)$ was slightly less than in previous studies of $\mathrm{AB}$ athletes running a half-marathon in a tropical climate $(96-100 \%) .{ }^{17,23}$ 
Furthermore, in these studies there was a greater proportion of individuals with a $\mathrm{T}_{\mathrm{c}} \geq 40.0^{\circ} \mathrm{C}$ (40-56\%) which is likely due to the greater oppressiveness of the environment and heat production from running for $>90 \mathrm{~min}$. However, in the current study, the percentage of athletes $\geq 40.0^{\circ} \mathrm{C}(29 \%)$ was still higher than $\mathrm{AB}$ individuals competing in sprint or Olympic distance triathlons $(0 \%),{ }^{22}$ running $15 \mathrm{~km}$ in a temperate environment $(13 \%),{ }^{17}$ or elite $\mathrm{AB}$ cyclists in a recent World Championships in a hot, dry climate $(25 \%) .{ }^{20}$ These findings provided context to the level of strain faced by paratriathletes in the heat. As paratriathletes display such significant thermoregulatory strain in the heat, event organisers must consider first aid provision at races with challenging environmental conditions, such as the 2020 Tokyo Paralympic Games, ${ }^{29}$ for the rapid treatment of potential heat illness. This may be particularly pertinent when ambulant athletes are running, and their $\mathrm{T}_{\mathrm{c}}$ is greatest, as shown here. Furthermore, cut-off values for event postponement or distance modification should be considered to lessen the thermoregulatory strain imposed by environmental conditions.

To date, research typifying the thermoregulatory strain of Paralympic sports has been predominantly confined to wheelchair court sports of athletes with an SCI. ${ }^{2-4}$ The sole study of a Paralympic endurance sport described a peak $\mathrm{T}_{\mathrm{c}}$ of $40.4^{\circ} \mathrm{C}$ at the end of a $42 \mathrm{~km}$ race, in temperature conditions $\left(20.0\right.$ to $\left.22.0^{\circ} \mathrm{C}\right)$, in a single, male, handcyclist. ${ }^{4}$ This study, which now extends scientific understanding by including athletes of mixed impairments, found there were differences in the temperature responses between impairment groups. Specifically, changes in $\mathrm{T}_{\mathrm{c}}$ during the run segment were significantly greater for PTVI than PTWC, comprised mostly of athletes with an SCI. This is presumably due to the considerably disparate race demands across paratriathlon, depending on athletes' race categories. During the run segment, PTWC athletes in a racing wheelchair utilise less active musculature and travel at a greater velocity, thus are exposed to greater air flow for convective heat loss compared to ambulant runners. Therefore, it is not surprising that changes in $T_{c}$ were significantly greater for PTVI athletes when running compared to those in PTWC as heat production was greater whilst heat dissipative potential was lower.

At the time of data collection, ITU paratriathlon races permitted wetsuit use up to a water temperature of $28.0^{\circ} \mathrm{C}$ although this has subsequently been changed to $24.6^{\circ} \mathrm{C}$ based on the findings of the present study. ${ }^{30}$ Here, it was shown that wetsuit use resulted in a significantly elevated SWIM $\mathrm{Sind}_{\mathrm{e}}$ and $\mathrm{SWIM}_{\mathrm{av}} \mathrm{T}_{\mathrm{c}}$. It is noteworthy that of the 16 athletes reporting symptoms of heat illness, 10 wore a wetsuit. Moreover, those that were symptomatic also displayed a significantly greater $\mathrm{SWIM}_{\mathrm{end}}, \mathrm{SWIM}_{\mathrm{av}}, \mathrm{SWIM}_{\Delta}, \mathrm{T} 1, \mathrm{BIKE}_{1}, \mathrm{BIKE}_{2}, \mathrm{BIKE}_{\mathrm{av}}$ and RUN $\mathrm{R}_{\mathrm{av}}$. A high $\mathrm{T}_{c}$ rise early in exercise has been suggested to be implicated in heat illness genesis. ${ }^{23}$ Furthermore, the incidence of heat illness symptomatology was greater in the current study than elsewhere in $\mathrm{AB}$ athletes. ${ }^{16}, 18,20,22,31$ This may relate to paratriathletes' greater susceptibility for excessive thermoregulatory strain because of their physical impairments or lower aerobic fitness. ${ }^{32}$ Due to the significantly greater $T_{c}$ at various time points in the heat illness symptomatic group, the negative health consequences of elevated body temperatures during paratriathlon competition are highlighted. This supports recent evidence from LoganSprenger where two athletes with a $\mathrm{T}_{\mathrm{c}} \geq 39.2^{\circ} \mathrm{C}$ also displayed symptoms of heat illness. ${ }^{22}$

In the present study, there were differences in the $T_{c}$ responses between those who reported being prior acclimatised or acclimated to the heat. This is the first study to acknowledge this aspect during triathlon competition of any format. Specifically, RUN $N_{\text {end }} T_{c}$ and change in $T_{c} R U N_{\text {mid }}-R_{U} N_{\text {end }}$ were greater for those with prior chronic heat exposure. Racinais et al. ${ }^{31}$ have previously shown that peak $\mathrm{T}_{\mathrm{c}}$ during a $43 \mathrm{~km}$ cycling time-trial in the heat was unchanged by heat acclimatisation, albeit with a greater cycling power output than pre-acclimatisation. This may relate to the beneficial thermoregulatory adaptations of chronic 
heat exposure permitting a greater relative intensity and thus metabolic heat production during racing. However, it is not known how other thermoregulatory variables (e.g., $\mathrm{T}_{\mathrm{sk}}$, heart rate, sweat rate) may have differed between groups in the current study.

A novel feature of this study was to record $\mathrm{T}_{\text {sk }}$ changes throughout a field-based competitive triathlon. In the subset of athletes in whom $T_{\mathrm{sk}}$ was measured, there was no significant change over time. although large variation present with a small sample size. There was a significant difference in the $\mathrm{T}_{\text {sk }}$ changes across the race segments; specifically, the change was greater during cycling than running. The drop in $\mathrm{T}_{\mathrm{sk}}$ during the cycling segment is presumably due to greater wind velocity augmenting convective cooling at the periphery. ${ }^{18}$

\section{PRACTICAL APPLICATIONS}

The current study builds on previous research of thermoregulation during competitive sporting events by investigating the sport of paratriathlon whilst utilising regular sampling frequencies. However, the small sample size limited the ability to determine further impairment-specific responses. Similarly, the restricted number of athletes in whom $\mathrm{T}_{\mathrm{sk}}$ was measured constrains the likelihood of revealing true changes throughout triathlon races. Lastly, the study relied upon participant reports of several parameters (e.g., fluid intake, heat acclimation/acclimatisation state, heat illness symptoms) which were not confirmed objectively. Similarly, there was no account of, or control for, the use of contraception in female athletes nor so athletes' hydration status pre-race.

Nonetheless, from these data, coaches, practitioners and medical staff now have a better understanding of the thermoregulatory strain imposed by paratriathlon competition in the heat. This should subsequently prompt the implementation of strategies to alleviate such strain. For example, athletes would be prudent to look to utilise heat acclimation/acclimatisation strategies due to the potential for improvements in thermoregulatory variables. ${ }^{12}$ Furthermore, pre- or per-race cooling strategies may be employed and modified depending on athletes' race category and expected $\mathrm{T}_{\mathrm{c}}$ responses (e.g., the use of cooling strategies when handcycling for PTWC athletes and when running for ambulant athletes). ${ }^{12}$ Additionally, athletes should seek strategies to ameliorate thermal strain in races such as by minimising fluid $\operatorname{losses}^{22}$ and adopting an evenly-paced race. Event organisers ought to consider medical provision in similar situations to the present study due to the high propensity for heat illness symptomatology whilst also reflecting upon utilising defined weather limits, using wet-bulb globe temperature or otherwise, to determine the need for race alteration or postponement.

\section{CONCLUSIONS}

Paratriathletes face significant thermoregulatory strain during competition in the heat, as evidenced by high $\mathrm{T}_{\mathrm{c}}$ and prevalence of self-reported heat illness symptoms, although the effect on $\mathrm{T}_{\mathrm{sk}}$ is still ambiguous. Athletes' $\mathrm{T}_{\mathrm{c}}$ is typically greatest during the run segment whilst those with a VI display significant increases in $\mathrm{T}_{\mathrm{c}}$ during this phase. Finally, it appears that the use of a wetsuit substantially elevates $T_{c}$ and may be linked to the incidence of heat illness, but this requires verification by controlled laboratory studies or further field trials.

\section{Acknowledgements}

The authors thank the ITU and race organising committees for their endorsement and operational support 
1. Webborn ADJ. Heat-related problems for the Paralympic Games, Atlanta 1996. Br J Ther Rehabil. 1996;3(8):429-436.

2. Griggs KE, Havenith G, Price MJ, Mason BS, Goosey-Tolfrey VL. Thermoregulatory responses during competitive wheelchair rugby match play. Int J Sports Med. 2017;38(3):177-183.

3. Veltmeijer MTW, Pluim B, Thijssen DHJ, Hopman MT, Eijsvogels TM. Thermoregulatory responses in wheelchair tennis players: A pilot study. Spinal Cord. 2014;52(5):373-377.

4. Abel T, Schneider S, Platen P, Strüder HK. Performance diagnostics in handbiking during competition. Spinal Cord. 2006;44(4):211-216.

5. Crandall CG, Davis SL. Cutaneous vascular and sudomotor responses in human skin grafts. J Appl Physiol. 2010;109(5):1524-1530.

6. Klute GK, Rowe GI, Mamishev AV, Ledoux WR. The thermal conductivity of prosthetic sockets and liners. Prosthet Orthot Int. 2007;31(3):292-299.

7. Maltais D, Wilk B, Unnithan V, Bar-Or O. Responses of children with cerebral palsy to treadmill walking exercise in the heat. Med Sci Sports Exerc. 2004;36(10):16741681.

8. Ward KH, Meyers MC. Exercise performance of lower-extremity amputees. Sports Med. 1995;20(4):207-214.

9. Kloyiam S, Breen S, Jakeman P, Conway J, Hutzler Y. Soccer-specific endurance and running economy in soccer players with cerebral palsy. Adapt Phys Activ $Q$. 2011;28(4):354-367.

10. Webborn N, Van de Vliet P. Paralympic medicine. Lancet. 2012;380(9836):65-71.

11. Runciman P, Tucker R, Ferreira S, Albertus-Kajee Y, Derman W. Paralympic athletes with cerebral palsy display altered pacing strategies in distance-deceived shuttle running trials. Scand J Med Sci Sports. 2016;26(10):1239-1248.

12. Racinais S, Alonso JM, Coutts AJ, et al. Consensus recommendations on training and competing in the heat. Br J Sports Med. 2015;49:1164-1173.

13. Racinais S, Wilson MG, Périard JD. Passive heat acclimation improves skeletal muscle contractility in humans. Am J Physiol Regul Integr Comp Physiol. 2017;312(1):R101R107.

14. Laursen PB, Suriano R, Quod MJ, et al. Core temperature and hydration status during an Ironman triathlon. Br J Sports Med. 2006;40(4):320-325.

15. Galloway SD, Maughan RJ. Effects of ambient temperature on the capacity to perform prolonged cycle exercise in man. Med Sci Sports Exerc. 1997;29:1240-1249.

16. Lee JKW, Nio AQN, Lim CL, Teo EY, Byrne C. Thermoregulation, pacing and fluid balance during mass participation distance running in a warm and humid environment. Eur J Appl Physiol. 2010;109(5):887-898.

17. Veltmeijer MTW, Eijsvogels TMH, Thijssen DHJ, Hopman MT. Incidence and predictors of exertional hyperthermia after a $15-\mathrm{km}$ road race in cool environmental conditions. $J$ Sci Med Sport. 2015;18(3):333-337.

18. Baillot M, Hue O. Hydration and thermoregulation during a half-Ironman performed in tropical climate. J Sports Sci Med. 2015;14(2):263-268.

19. Del Coso J, González C, Abian-Vicen J, et al. Relationship between physiological parameters and performance during a half-Ironman triathlon in the heat. J Sports Sci. 2014;32(18):1680-1687.

20. Racinais S, Moussay S, Nichols D, Travers G, Belfekih T, Schumacher YO, Périard JD. (2018). Core temperature up to $41.5^{\circ} \mathrm{C}$ during the UCI Road Cycling World 
Championships in the heat. Br J Sports Med. Published Online First: 01 December 2018. doi: 10.1136/bjsports-2018-099881.

21. Bergeron MF, Bahr R, Bärtsch $\mathrm{P}$, et al. International Olympic Committee consensus statement on thermoregulatory and altitude challenges for high-level athletes. Br J Sports Med. 2012;46(11):770-779.

22. Logan-Sprenger HM. Fluid balance and thermoregulatory responses of competitive triathletes. J Therm Biol. 2019;79:69-72.

23. Byrne C, Lee JKW, Chew SAN, Lim CL, Tan EY. Continuous thermoregulatory responses to mass-participation distance running in heat. Med Sci Sports Exerc. 2006;38(5):803-810.

24. Byrne C, Lim CL. The ingestible telemetric body core temperature sensor: a review of validity and exercise applications. Br J Sports Med. 2007;41(3):126-133.

25. Bongers CCWG, Daanen HAM, Bogerd CP, Hopman MTE, Eijsvogels TMH. Validity, reliability, and inertia of four different temperature capsule systems. Med Sci Sports Exerc, 2018;50(1):169-175.

26. Coris EE, Walz SM, Duncanson R, Ramirez AM, Roetzheim RG. Heat illness symptom index (HISI): A novel instrument for the assessment of heat illness in athletes. South Med J. 2006;99(4):340-345.

27. Ramanathan NL. A new weighting system for mean surface temperature of the human body. J Appl Physiol. 1964;19(3):531-533.

28. Périard JD, Racinais S, Sawka MN. (2015). Adaptations and mechanisms of human heat acclimation: Applications for competitive athletes and sports. Scand J Med Sci Sports. 2015;25(S1):20-38.

29. Hosokawa Y, Nagata T, Hasegawa M. Inconsistency in the standard of care-toward evidence-based management of exertional heat stroke. Front Physiol. 2019;10:1-6.

30. International Triathlon Union. ITU Competition Rules. Retrieved January 2019 from https://www.triathlon.org/uploads/docs/itusport_competition-rules_2019.pdf

31. Racinais S, Périard JD, Karlsen A, Nybo L. Effect of heat and heat acclimatization on cycling time trial performance and pacing. Scand J Med Sci Sports. 2015;47(3):601-606.

32. Gardner JW, Kark JA, Karnei K, Sanborn JS, Gastaldo E, Burr P, Wenger CB. Risk factors predicting exertional heat illness in male Marine Corps recruits. Med Sci Sports Exerc. 1996;28(8):939-944. 


\section{FIGURE CAPTIONS}

407 Figure 1: Whole-group core temperature changes throughout the race. Dots are individual data; 408 black line indicates group mean. *Significantly lower than all other time points $(\mathrm{p}<0.001)$. $409 \dagger$ Significantly lower than $R U N_{\text {mid }}(p \leq 0.039)$. $¥$ Significantly greater than all other time points $410 \quad(p \leq 0.031)$. $\S$ Significantly greater at each time point $(p \leq 0.016)$.

411 Figure 2: Core temperature changes and heat illness symptomatology throughout the race.

412 Circles are symptomatic, triangles are asymptomatic individuals, lines are group means.

$413 *$ Significantly greater in symptomatic group $(\mathrm{p} \leq 0.046)$.

414 Figure 3: Skin temperature changes throughout the race. Dots are individual data; black line 415 indicates group mean. 


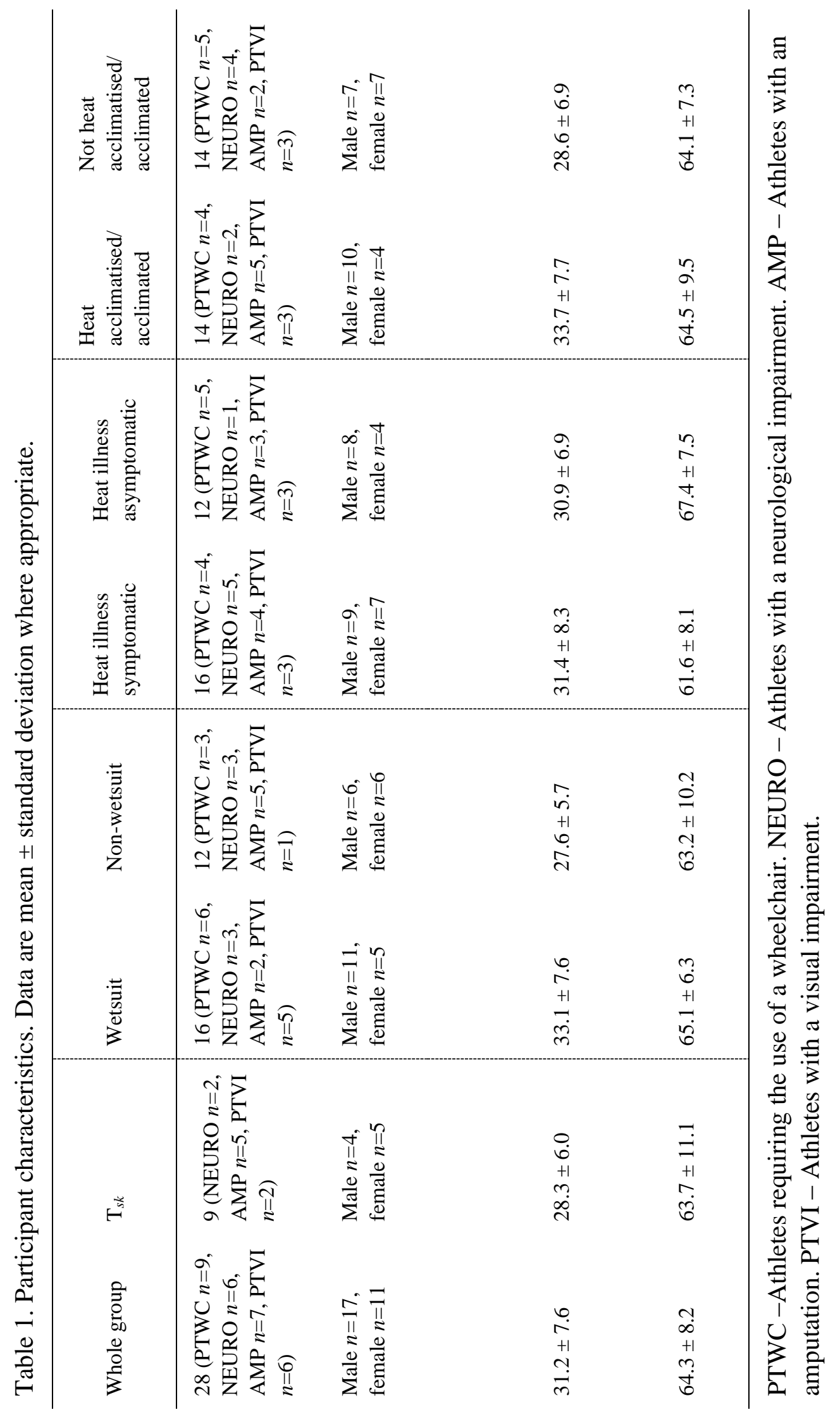




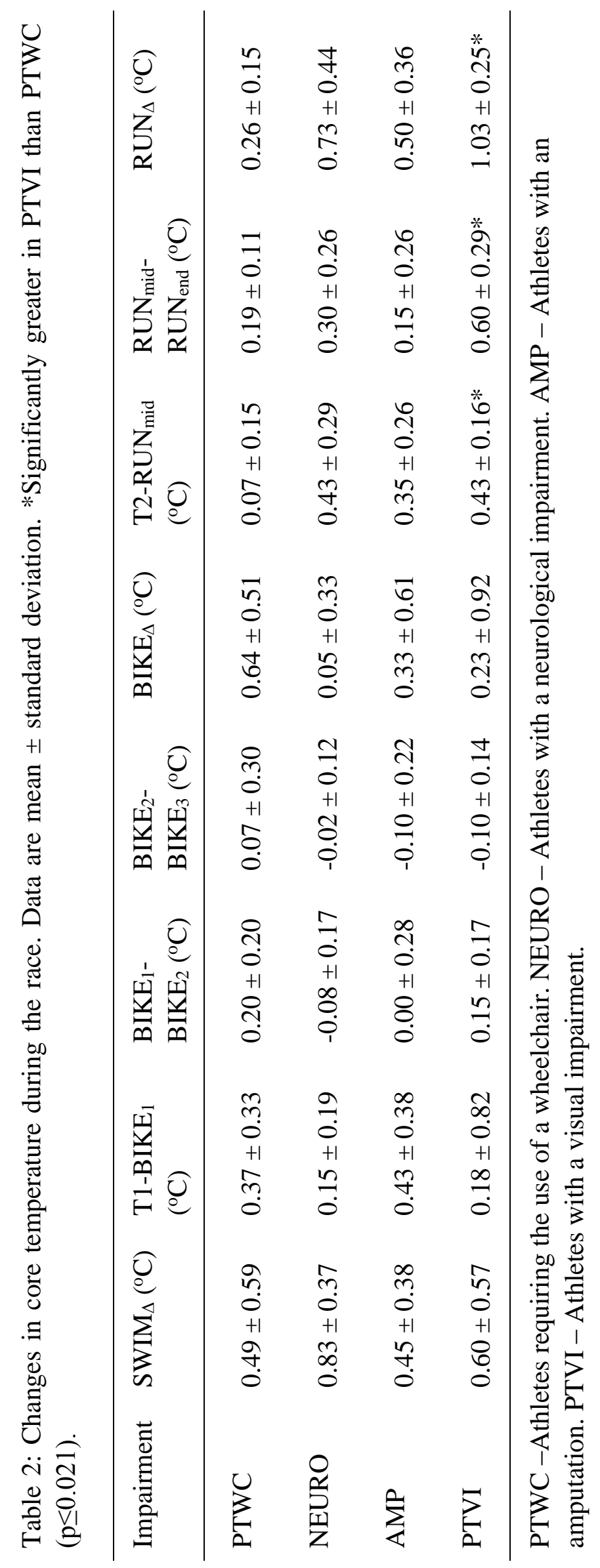




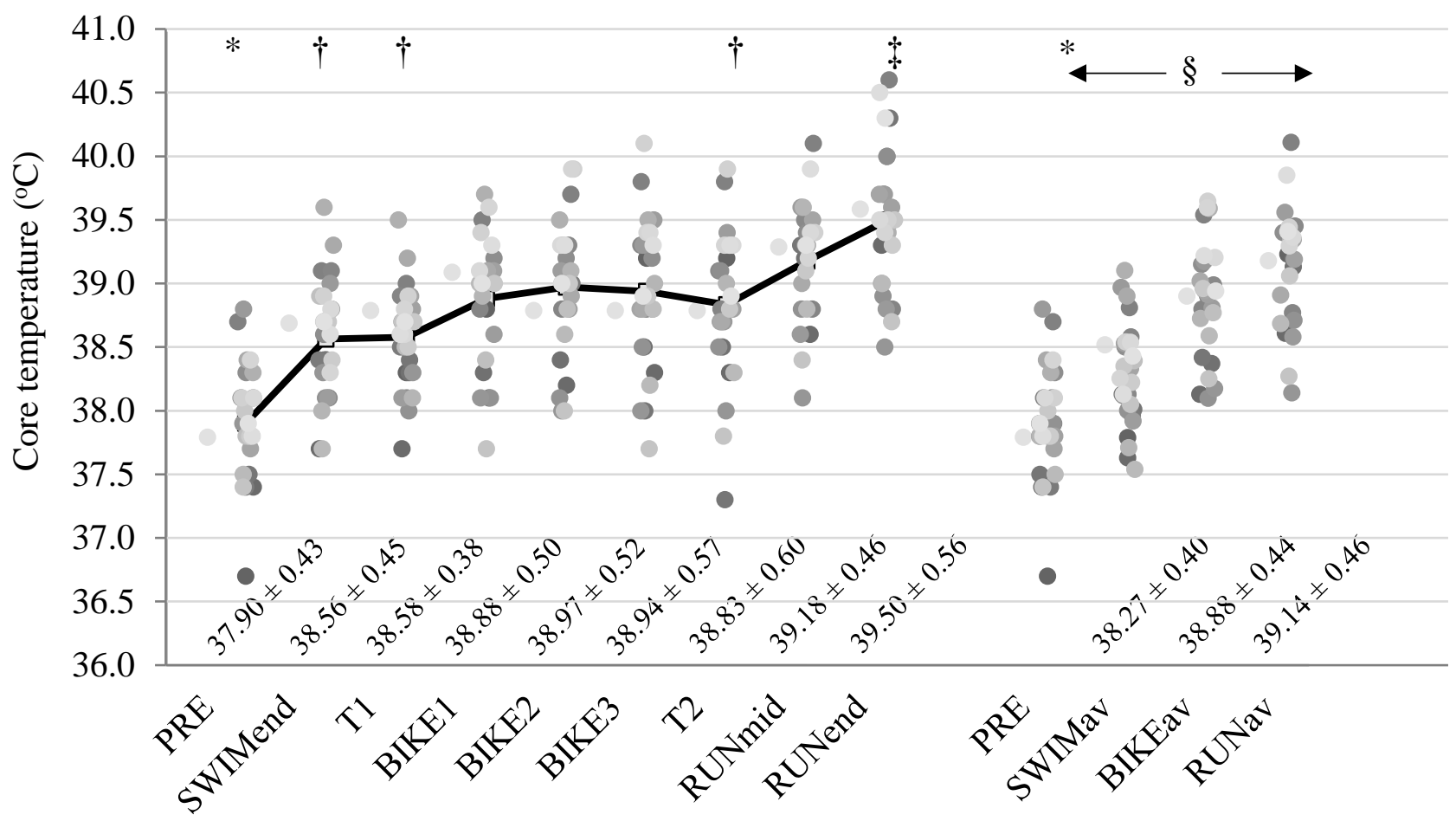

Time point

418

419 Figure 1: Whole-group core temperature changes throughout the race. Dots are individual data;

420 line indicates group mean. *Significantly lower than all other time points $(\mathrm{p}<0.001)$.

$421 \uparrow$ Significantly lower than $R U N_{\text {mid }}(\mathrm{p} \leq 0.039)$. $†$ Significantly greater than all other time points

$422(\mathrm{p} \leq 0.031)$. Significantly greater at each time point $(\mathrm{p} \leq 0.016)$.

423

424 


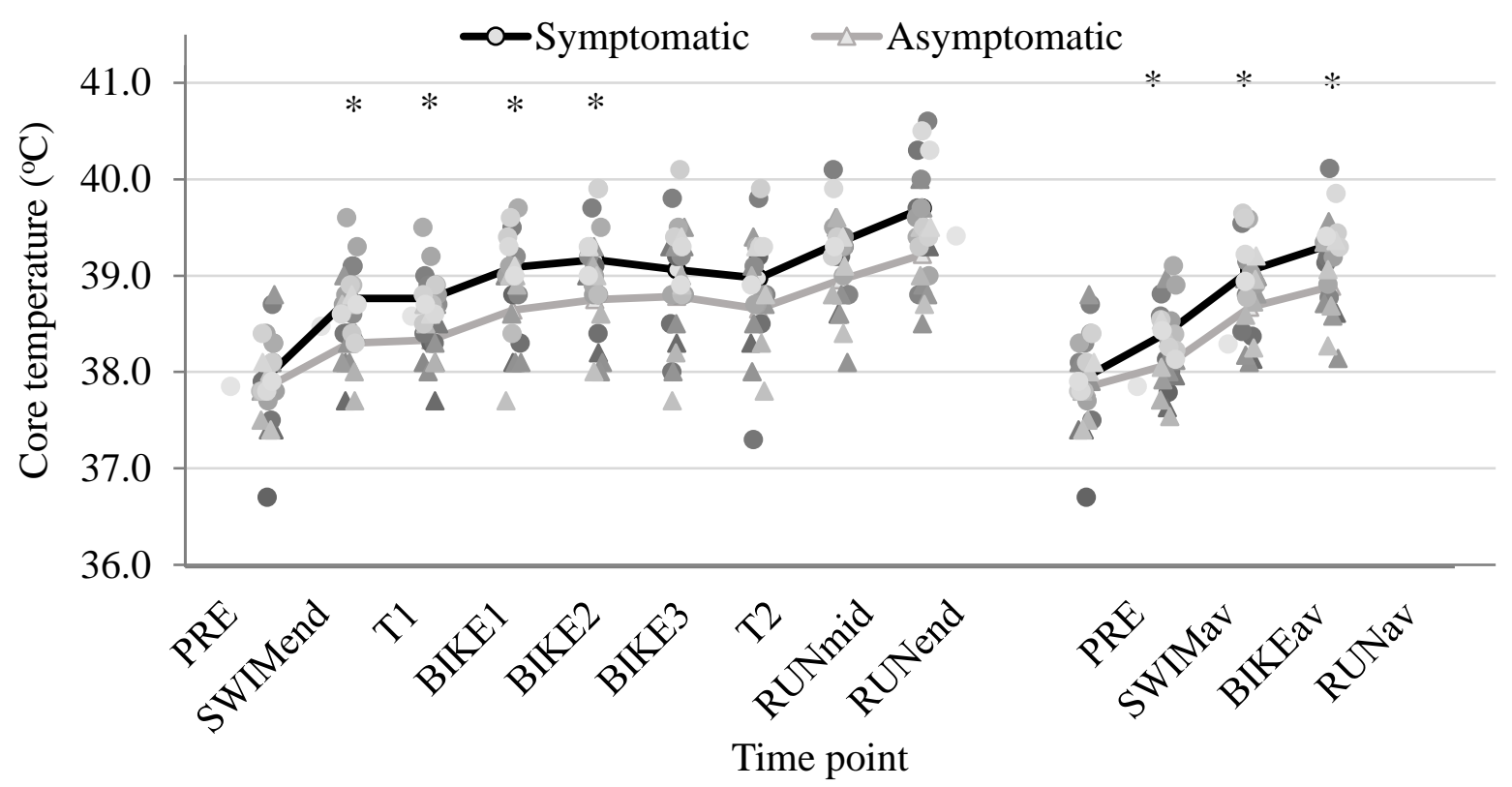

425

Figure 2: Core temperature changes and heat illness symptomatology throughout the race.

427 Circles are symptomatic, triangles are asymptomatic individuals, lines are group means.

428 *Significantly greater in symptomatic group $(\mathrm{p} \leq 0.046)$.

429 


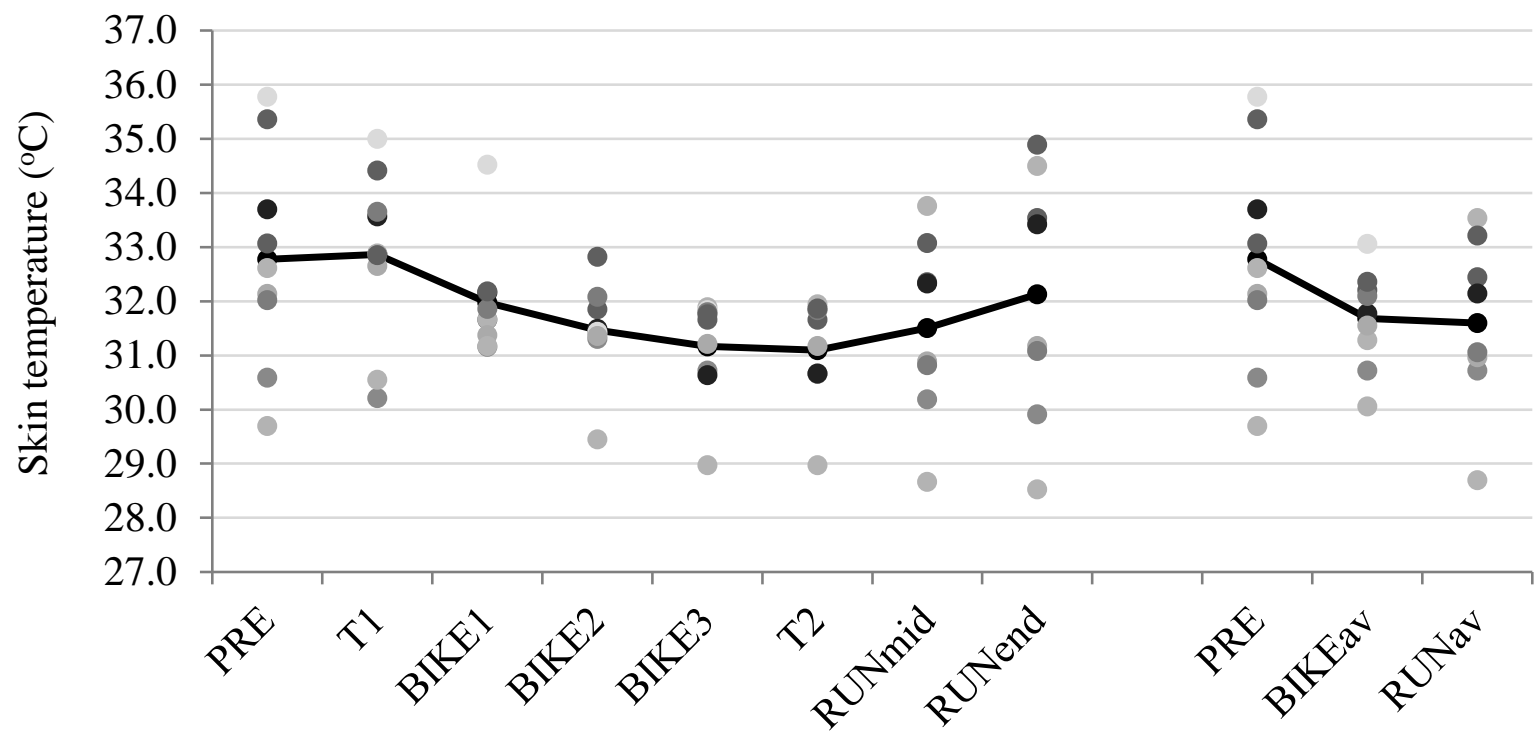

Time point

430

431 Figure 3: Skin temperature changes throughout the race. Dots are individual data; line indicates 432 group mean.

433

434 